\title{
DILEMAS DO PENSAMENTO POLÍTICO: FAMÍLIAS INTELECTUAIS E AS INTERPRETAÇÕES SOBRE O BRASIL
}

\author{
Vera Alves Cepêda
}

Não é tarefa fácil apresentar e comentar o livro Linhagens do pensamento político brasileiro, de autoria de Gildo Marçal Brandão. Pesa em primeiro lugar o fato de que esse livro nasceu da livre-docência defendida pelo autor, no final de 2004, na Universidade de São Paulo, correspondendo assim a uma pesquisa de fôlego e a uma maturação intelectual resultante de longa trajetória na vida acadêmica. Mas pesa ainda mais a envergadura teórica da obra, o alcance que representa para o conjunto da Ciência Política brasileira e o debate que propõe sobre a natureza e a questão da institucionalização dessa mesma Ciência Política. Além de obra madura, Linhagens do pensamento é também um desafio intelectual para aqueles pesquisadores que trabalham com o problema político brasileiro no percurso de sua formação enquanto um legado intelectual.

O texto é composto por três movimentos analíticos combinados: uma reflexão densa e profunda sobre o estado da arte dos trabalhos produzidos sobre pensamento social brasileiro, estudos específicos sobre alguns autores nacionais em seu vínculo com as famílias intelectuais propostas na teoria das linhagens e uma abordagem sobre a intelligentsia na condição periférica. Nesse último ponto, Brandão cerra fileiras contra a atual entronização do modelo de pesquisa empírico e descritivo na Ciência Política brasileira, responsabilizado pelo esvaziamento da reflexão crítica desses estudos. A divisão temática assim apresentada permite reagrupar os capítulos do livro da seguinte forma: teoria (primeira parte e capítulo um), estudo(s) sobre o pensamento social (capítulos dois e três), periferia, pesquisa e mudança paradigmática na Ciência Política (toda a segunda parte).

Incidindo em objetos de natureza diversa - teoria social, análise de autores ou instituições e projetos de pesquisa - o livro possui, como unidade condutora, a elaboração de uma teoria de alcance epistemológico, apresentada na primeira parte do texto, que possibilita ao pesquisador compreender (em vez de descrever) o leque do pensamento social brasileiro gerado em mais de cem anos de vigorosa e diversificada produção intelectual. A seguir tentarei apresentar um apanhado geral sobre os movimentos de Linhagens, com atenção especial para a questão teórica que embasa a constituição do texto e para o problema da "metodolatria" e a conversão dos estudos políticos em uma ciência aos moldes do institucionalismo norte-americano.

Linhagens é aberto com um desafio: discutir a percepção, em boa medida hegemônica no campo dos estudos sobre a política brasileira, que organiza e entende o pensamento político nacional segundo uma divisão entre a fase ensaísta e a fase científica. Assim, as Ciências Sociais como um todo teriam se consolidado no momento em que a interpretação foi substituída pela análise apoiada no modelo acadêmico, na pesquisa embasada empiricamente e consoante o tratamento teórico oferecido pela bibliografia especializada da área. A criação, no inicio dos anos 1930, da Escola de Sociologia e Política e da Faculdade de Filosofia, Ciências e Letras da Universidade de São Paulo seriam o marco inicial desse processo. Posteriormente, a contribuição teórico-metodológica da Cadeira I de Sociologia da USP (normatizada em sua maior parte sob a orientação de Florestan Fernandes e de seu grupo), o surgimento dos institutos de pesquisa nos anos 1950 e 1960 e a expansão da pós-graduação no país teriam conformado o caráter científico da produção sociológica, antropológica e política ${ }^{1}$.

Essa taxionomia toma como elemento distintivo uma condição pré-científica atribuída a toda a vasta reflexão política anterior ao surgimento das instituições acadêmicas e de pesquisa, opondo e validando, mesmo

\footnotetext{
${ }^{1}$ É notória a influência da coletânea de trabalhos organizada por Sérgio Miceli (2001). A classificação é justa se o critério que se adota é o da configuração de uma área de saber a partir da criação de suas instituições e do tratamento especializado. Porém, a questão é saber se há possibilidade de outros critérios e outras maneiras de observar-se o mesmo fenômeno.
} 
sem intenção consciente, a produção empírica à reflexão, o cânone institucional à mescla heteróclita e contraditória das condições históricas. Retomar esse debate não é passo tranqüilo e muito menos irrelevante. Sob essa questão abriga-se o problema do como e do o quê deve ser estudado na complexa área dos estudos sobre a política. Brandão contesta, em primeiro lugar, a naturalização normalmente aceita dessa cronologia dicotômica, em seguida problematiza a questão de como classificar os trabalhos de pesquisa que elegem a produção intelectual dos chamados autores clássicos do pensamento político brasileiro: ao trabalharem com obras de tradição ensaística, essas análises pertencem ao campo dos estudos de Teoria Política brasileira? Ou seriam estudos literários, históricos ou de Sociologia da Cultura? Pensar uma ciência da política apenas no momento institucional, acadêmico e metodologicamente orientado implica desprezar as grandes contribuições que gestaram o próprio e desdobrado surgimento dessa área de saber em particular. Implica também esquecer a enorme contribuição deixada pelos vários autores que escreveram e pensaram a questão da construção nacional (passando por temas como a relação entre Estado, cultura e sociedade ou modernização, democracia e desenvolvimento) e que surgiu no seio do ensaísmo.

Foi na elaboração teórica seminal de autores clássicos, como "Visconde de Uruguai, Tavares Bastos, Silvio Romero, Joaquim Nabuco, Rui Barbosa, Euclides da Cunha, Alberto Torres, Oliveira Viana, Azevedo Amaral, Gilberto Freire, Sérgio Buarque de Holanda, Nestor Duarte, Caio Prado Jr., Raimundo Faoro, Vitor Nunes Leal, Guerreiro Ramos, Florestan Fernandes, Celso Furtado, etc.” (BRANDÃO, 2007, p. 25), que o léxico e a gramática dos problemas políticos nacionais foram gerados. Esse movimento original deixou herança na compreensão, na interpretação e na orientação das matrizes do pensamento político nacional. Por conta dessa força e importância cristalizadas historicamente não podemos hoje abrir qualquer discussão sobre o desempenho e o futuro político da nação, sobre o desenho e o peso das instituições, sobre o conjunto de valores que modelam a interpretação e a ação sem, em algum momento, tangenciar uma contribuição ou uma tematização construída no passado por esses autores. Dois seriam os motivos, salientados por Brandão, capazes de explicar essa persistência, quase renitente, do eco dos clássicos no debate moderno. O primeiro é o conjunto de fatores que explicam a conversão de um autor ou obra em um clássico, determinado, por um lado, pela adequação do pensamento à realidade da qual emerge e, de outro, pela capacidade teórica de transcender esses limites originários em direção a uma ação orientada racional e ideologicamente, tornando-se relevante e aglutinador de forças sociais. O elo entre o ajuste ao desafio historicamente colocado e a recepção socialmente alcançada é demonstrado no consenso que a obra adquire, quer como vitoriosa no momento em que se constrói, quer na recuperação tardia e retomada do tema. O segundo motivo é que a influência exercida por essas interpretações e teorias transpareceu nos processos históricos reais, acabando por desaguar (de maneira direta ou cumulativa) na construção do presente. É a tenacidade com que velhos temas brotam do solo do debate e das análises acadêmicas que reforça a tese de que há um leito comum, uma reapropriação constante e cumulativa que origina uma constelação móvel no eixo da história. Certo conjunto de idéias - principalmente, de idéias-chave - possui dinâmica própria, como instituições sociais, e somente podem ser compreendidas sob o esforço cognitivo historicista.

Nesse ponto, um dos esforços de Brandão é tentar discernir, no solo movediço dos estudos sobre pensamento social e político, um percurso e um método seguro de investigação que escape da leitura descritiva ad hoc, da exegese purista, mas que se afaste também de uma reconstrução hermenêutica livre. Lógicas, movimentos semânticos, percurso de produções diversas que anelam entre si horizontes cognitivos e pressupostos teóricos. Diferentemente de uma história dos intelectuais ou das instituições, da história das coteries ou história das idéias, o autor propõe que expressão e forma sejam conectadas como um movimento do "socialmente constituído”. Pensamento político não como resultado linear das contrações da realidade, nem como utopia autônoma e idealista, mas como síntese dos embates e propostas que, emergindo do tecido social, ocupam a arena simbólica das idéias e abstrações teóricas e voltam a ela, realizando-se. Tensão e superação que, travejadas pelas linhas temporais, expressam o campo mais dilatado da política - a ação - oscilando entre o real e o representado, o dado e a elaboração, o passado, presente e o futuro como um arco estruturado e dotado de sentido.

É somente sob esse viés que a inédita e poderosa contribuição do texto de Brandão para os estudos sobre o pensamento político e sobre os múltiplos enfoques da Ciência Política pode ser percebida. E é nesse ponto, também, que a maturidade e o amplo espectro de seu trabalho, debruçado sobre um pensamento político com quase dois séculos de existência, faz-se sentir. Linhagens é, simultaneamente, uma teoria interpretativa de longo alcance, um método de investigação e um produto analítico sobre autores e momentos institucionais da 
política e do pensamento social brasileiro. Compõe-se, assim, de um pressuposto teórico (uma maneira de entender o processo social por meio do pensamento social), um método de pesquisa e uma tese interpretativa.

Como pressuposto, a partir do reconhecimento das múltiplas possibilidades por meio das quais podem-se observar os autores que pensaram o Brasil, Linhagens efetua uma escolha de leitura. Inúmeros e sérios trabalhos analisam os pensadores e suas obras na perspectiva exegética, procurando os nexos internos de sua lógica ou as características intrínsecas e singulares, conectando-os nesse movimento genético com os problemas coetâneos. Outros observam a origem social dos autores e de seus produtos. Alguns trabalhos enfocam a curta duração enquanto outros procuram a longa duração. A heterogeneidade de recursos é rica na mesma proporção em que no método escolhido é revelada a matriz teórica com a qual os fenômenos sociais são entendidos - a epistemologia revela, nesse caso, a ontologia. Na ótica desenvolvida em Linhagens, autores e textos são tomados como uma tensão sincrônica e diacrônica, na dimensão interna e no embate externo. As produções intelectuais absorvem e reelaboram a realidade histórica e social em sua formulação (dimensão interna); passam pela legitimação na arena intelectual e política, em renhida disputa com outras interpretações (dimensão externa) e acabam por contribuir para a transformação da sociedade, alterando os quadros mentais e materiais, abrindo um novo ciclo de temas e problemas ${ }^{2}$. O pensamento pode e deve ser tomado, enquanto um diálogo, como processo que inflecte e reflete a vida política nacional. Ao contrário de uma ciência da descrição e de uma concepção estática da realidade social, Brandão afirma o pensamento enquanto uma produção cinzelada pelas contradições e contrastes históricos. Um pensamento político com atores e interesses, um conhecimento que, aceitando como condição sine qua non a objetividade e a neutralidade (oposta ao uso faccioso da ciência), atende as limitações axiológicas e matizadas pela condição do pensamento socialmente determinado. Não há pensamento político gestado fora do campo do enfrentamento - na sua origem, na sua lapidação cognitiva e no seu uso.

Como método, a proposta de Linhagens é analisar a tradição intelectual brasileira procurando discernir as permanências e as mudanças que ficam nos textos que a compõe. Não se trata aqui de uma análise dos elementos formais do discurso, mas da detecção de dois elementos socialmente constituídos relevantes e que aparecem subjacente à obra ou pensamento de cada autor. O primeiro, na observação da receptação do influxo social, enquanto mecanismo que permite observar a presença de elementos de cunho: a) histórico - agenda de problemas e temas; b) teórico - pela maneira ou ferramentas lógico-ideacionais utilizadas no recorte e tratamento dessa agenda; c) político - pelo que recusa (disputa simbólica com outras formas de pensamento existentes diacrônica ou sincronicamente). O segundo elemento relevante é o ajuste intelectivo que cada autor produz e que - flexionado entre o empuxo social, o tratamento lógico-discursivo e a vontade de orientar (enquanto ação prática ou campo mais rarefeito da weltanschauung) - gera escolhas e configura-se como produto do pensamento socialmente produzido, podendo ser, nos termos mannheimianos, ideologia, utopia ou síntese.

O estabelecimento do estreito nexo entre o pensamento político e a vida política stricto sensu funciona como uma tese e um método balizador para o efetivo mergulho no conjunto do pensamento social brasileiro. É aqui que Brandão oferece aos estudos políticos uma nova maneira de analisarmos o coletivo das contribuições legadas por aqueles autores que vêm pensando os temas da vida pública nacional desde a segunda metade do século XIX: a teoria da existência de linhagens, ou de famílias, que se formaram como respostas intelectuais aos problemas postos pela história e pela sociedade brasileira e que se reciclam no tempo - dado que a política é menos o epifenômeno da vida curta dos governantes do que a lógica das instituições e das idéias que a estruturam. O estudo do "[...] pensamento político-social foi capaz de formular ou de discriminar na evolução política e ideológica brasileira a existência de “estilos” determinados, formas de pensar extraordinariamente persistentes no tempo, modos intelectuais de se relacionar com a realidade que subsumem até mesmo os mais lídimos produtos da ciência institucionalizada, estabelecendo problemáticas e continuidade que permitem situar e por sob nova luz muita proposta política e muita análise científica atual” (BRANDÃO, 2007, p. 29).

No argumento desenvolvido na primeira parte de Linhagens, Brandão oferece ao exame a classificação do variegado leque da produção intelectual segundo o agrupamento em quatro famílias de pensamento basilares:

2 Ao contrário de outras áreas dentro das Ciências Humanas, o pensamento político possui como essência o vínculo indissolúvel com a mudança. Assim, a sua laboração reflete problemas e sua finalização acaba por infletir a percepção de futuro e a recusa de projetos rivais. 
o idealismo orgânico, o idealismo constitucional, o pensamento radical de classe média e o marxismo de matriz comunista. Essas categorias, amarradas por Brandão num agregado coerente e sistêmico, já apareceram dispersas em um e outro momento do debate levado a cabo por autores e estudiosos da política brasileira. A noção de idealismo orgânico e constitucional é parte da original e significativa contribuição de Oliveira Viana (1927); o pensamento radical de classe média, como assinala Brandão, origina-se de uma anterior formulação de Antonio Cândido (1974); já a amarração da tipologia do marxismo de matriz comunista é conceito desenvolvido por Brandão em trabalho anterior também de muito fôlego (cf. BRANDÃO, 1997).

No entanto, esses tipos ideais ou classificatórios somente ganharam a dimensão de uma teoria fechada sobre a genealogia do pensamento social brasileiro a partir do esforço teórico de Brandão; é somente com o cruzamento de uma análise encadeada e global das principais obras políticas ${ }^{3}$ com uma percepção do processo político e histórico real, que se torna possível compreender as linhas de força que orientam a lógica do pensamento social em cada momento, em cada autor ou obra específica. A noção de famílias intelectuais amarra em uma abordagem processual e global as partes e os momentos de criação e ressignificação dos produtos do pensamento. Esse é o argumento que legitima a afirmação anterior de que Linhagens é obra madura e de envergadura, uma vez que não se trata do estudo exegético ou particular de um tema, um pensador, um período, mas a visão de conjunto - não como descrição ou taxionomia, mas como desvendamento de seus nexos e sentido.

Partindo da exploração conceitual (e de uma densa revisão de autores que trataram o tema da formação de um pensamento político brasileiro e de uma Ciência Política brasileira) ${ }^{4}$, Brandão fecha a primeira parte de seu texto com a apresentação da sua tese das linhagens. Uma vez que seu objetivo é transcender a mera classificação e alcançar a lógica dos estilos de pensamento, da análise comparada dos autores, infere como critério capaz de separar e aglutinar os diversos grupos intelectuais a delicada e problemática relação entre Estado e sociedade no Brasil. As quatro famílias propostas organizam-se como constelações girando sob a métrica dessa força magnética. Mas um cuidado impõe-se de saída: a valorização do Estado ou da sociedade não é fortuita, ao contrário, exige uma cadeia de raciocínios que nasce de um diagnóstico dos problemas sociais e é neste caminho que os argumentos que formam as linhagens são erigidos. A construção dos modelos do idealismo constitucional e idealismo orgânico, do pensamento radical de classe média e do marxismo de matriz comunista têm em comum uma agenda e avaliação de problemas sob um mesmo jaez que permite a configuração de diversas arquiteturas explicativas sobre os mesmo pilares e fundações. Assim, o idealismo orgânico, base do "programa conservador", somente pode orbitar em torno do Estado, quando reconhece a debilidade da sociedade como fonte da organização política. O modelo que privilegia a organicidade estatal origina-se na matriz interpretativa que inicia com Visconde do Uruguai e Oliveira Viana, e que depois tem vida longa nos vários momentos da vida política nacional, do tenentismo e de Vargas ao modelo burocrático-autoritário dos militares. Assenta-se na tese de que "não é possível construir um Estado liberal (e democrático) em uma sociedade que não seria liberal” (BRANDÃO, 2007, p. 46). Frente à fragilidade, plasticidade amorfa e subsunção das elites predatórias, somente o Estado pode ser aval da liberdade: "ao contrário da Europa e dos Estados Unidos, aqui o Estado não deveria ser tomado como a principal ameaça à liberdade civil, mas como sua única garantia” (idem, p. 47).

Já o idealismo constitucional ordena sua lógica argumentativa segundo o paradigma oposto: no Brasil, são as formas viciosas das instituições políticas que reprimem e deformam a sociedade. O percurso liberal, que têm como expressão autores distantes no tempo como Tavares Bastos e Raymundo Faoro (para quem o translado do modelo estatal português é origem de muitas de nossas vicissitudes institucionais e, depois, sociais), tem como mote geral a aposta de que a "boa lei produz a boa sociedade”. Essa família intelectual está ungida pelos laços de valorização da representação política, do federalismo e da visão institucional sub leges.

\footnotetext{
3 Lembrando que, principalmente na fase do ensaísmo, além do pensamento político temos como matéria-prima da análise as produções e interpretações das outras áreas irmãs: história, economia, antropologia, sociologia e filosofia.

4 São tratadas por Brandão, além dos autores anteriormente citados, outras contribuições importantes como as de Euclides da Cunha, Mario de Andrade, Tristão de Athayde, Inácio Rangel, Hélio Jaguaribe, Nelson Werneck Sodré, José Murilo de Carvalho, Wanderley Guilherme dos Santos, Francisco de Oliveira, Fernando Henrique Cardoso, Francisco Weffort, Fernando Novais, Sergio Miceli, Gabriel Cohn, Elide Rugai Bastos, Bolívar Lamounier, Luiz Werneck Vianna, Carlos Nelson Coutinho, Maria Isaura Pereira de Queiróz, Maria Victoria Benevides, entre outros inúmeros intelectuais e pesquisadores brasileiros.
} 
Ao ler o texto de Brandão, ocorreu-me que a transformação e modernização da sociedade brasileira empurrariam esse argumento para uma espécie de radicalização temática. Os autores do idealismo constitucional construíam sua argumentação por sobre o problema da formação nacional e, nesse momento, a questão importante era o legado (ou fardo) herdado da condição colonial e sua submissão às estruturas políticas metropolitanas. A liberdade do mercado (político e econômico, como o modelo original do liberalismo clássico) não era, como hoje, a chave explicativa. As questões institucionais do fim do século XIX e da primeira metade do XX eram trabalhadas no plano dos obstáculos à formação da sociedade (atores, racionalidade e instâncias). Depois da experiência nacional-desenvolvimentista e de seu esgotamento é que a liberdade concorrencial e o estímulo ao conflito parecem-me valorizados como recusa de um modelo de Estado que abafou a sociedade civil que já havia galgado o estatuto de modernidade.

Esse parêntese serve para ilustrar um apontamento de Brandão: o cadenciamento dos novos problemas impostos pela questão do subdesenvolvimento, do esforço desenvolvimentista, do projeto de modernização da sociedade brasileira e do amadurecimento da intelligentsia alterou os temas dos trabalhos intelectuais e da agenda de pesquisa no período. Nesse cenário, emergem com força as duas outras formas de pensar das linhagens: o pensamento radical de classe média e o marxismo de matriz comunista. Em boa medida, essas famílias trabalham com uma agenda mais moderna, na qual se destaca uma nova relação com o cenário externo - não mais herança colonial, mas periferia ou imperialismo. Também Estado e sociedade são repensados, agora sob o influxo da preocupação com o projeto de modernidade econômico e social em andamento e que tem como protagonistas novos as classes sociais e seu conflito estrutural.

Ao terminar de apresentar os contornos das quatro famílias intelectuais, o autor assinala a sua contínua reconfiguração e, muitas vezes, imbricação e combinação dos diálogos e das influências. Assim, argumentos que nascem numa família podem aparecer ressignificados em outro momento e em outra constelação. Mas o importante é que o traçado subjaz aos vários percursos e permite ao pesquisador, apavorado com a imensa riqueza do pensamento social brasileiro, encontrar, como alento, uma persistência que nos retira da ameaça de uma história social (e intelectual) contingente: "Num quadro como esse em que linhas quebradas escondem ou se superpõem a continuidades subterrâneas, não será surpresa constatar que tais "linhas evolutivas", "famílias intelectuais” ou " formas de pensar” não são naturais e imediatas. De fato, as conexões e continuidades entre representantes de uma mesma tendência ou família intelectual não são dadas espontaneamente [...] a fragmentária história brasileira levou a que pensadores começassem várias vezes do zero, ignorando os que antes deles chegaram a diagnósticos parecidos e soluções similares” (BRANDÃO, 2007, p. 63).

A segunda parte de Linhagens corresponde à aplicação do método proposto, ao deter-se no exame do legado de dois autores brasileiros: Oliveira Viana e Oliveiros Ferreira. A análise da obra de Oliveira Viana, com destaque para Populações Meridionais do Brasil (OLIVEIRA VIANNA, 1987) , é um estudo arguto e profundo do raciocínio que fundamentou as bases do idealismo orgânico no pensamento político brasileiro, obra da qual teria emanado, segundo o autor, o programa de pesquisa conservador. A partir do desvendamento da lógica que articula Populações Meridionais (temas, estruturação do método, configuração de uma análise sociológica e de uma inferência política), Brandão demonstra a seqüência de argumentos que cimenta o conjunto do pensamento de Oliveira Viana, presente também em outras obras: a debilidade dos nexos societários, as linhas de evolução do povo, o problema da dicotomia entre o país real e o país legal (ambas cinzeladas, em definitivo, em Instituições políticas brasileiras, de 1949) e, como corolário, a inferência da necessidade de pensar-se outra forma de organização que, longe da linearidade bacharelesca (e da valorização do liberalismo), apontava para o fortalecimento do papel do Estado.

Essa análise demonstra a vitalidade do método e da teoria propostas pelo modelo das formas de pensar, pois, a partir de uma obra lapidar (Viana), o tema da subsunção da sociedade fraca ao Estado demiurgo recupera uma clivagem do pensamento político anterior mesmo a Viana (Brandão reconhece esse percurso desde Visconde de Uruguai) e que orienta outras formulações futuras. Não obstante os vários matizes que no pensamento brasileiro vão valorizar a centralidade e a força do Estado (variando na finalidade perseguida e no projeto de futuro), desde a proposta agrarista ao modelo burocrático-autoritário, essa defesa tem em comum o pressuposto da fraqueza intrínseca e da condição amorfa da sociedade.

De maneira análoga é levado a cabo o exame do pensamento de Oliveiros Ferreira, com ênfase no momento histórico diferenciado no qual emerge uma série de novos fatos, como o agravamento das tensões entre as classes, a hegemonia alcançada pelo tema do subdesenvolvimento, do nacionalismo, da periferia (e sua sombra: o imperialismo) e o problema da América Latina. A consciência dos problemas políticos muda e as respos- 
tas aos dilemas socialmente estabelecidos fazem movimento de rotação, constituindo novas abordagens da qual uma que se torna madura e ativa é o pensamento radical de classe média.

Desse ponto em diante, o tom crítico eleva-se no texto. Brandão debruça-se nos capítulos subseqüentes na tarefa de esmiuçar o delicado tema da relação entre a ciência e a compreensão da política, levando a cabo uma dura crítica à fragmentação e esvaziamento de conteúdo que a institucionalização e o "amor ao método" têm produzido na nossa área de saber. Penso que, no desenho geral da obra, os capítulos sucedem-se de maneira coerente: entre a discussão teórica das linhagens e a discussão oposta da entronização do institucionalismo (e da hegemonia da "escolha racional") surge, como entreato, uma demonstração efetiva desse movimento.

Na etapa inicial da formação de uma tradição intelectual política brasileira, as duas formas de idealismo que disputavam o diagnóstico e o prognóstico de futuro, malgrado sua forte propensão ao ensaísmo, faziam-no com base numa visão que integrava o fenômeno político à dimensão histórica, sociológica e cultural e que lhe concedia um caráter contraditório e dinâmico. Esse é o método de Oliveira Viana, como o é em autores distantes como Caio Prado Jr., Florestan Fernandes e Celso Furtado. Pode pesar como critério de separação desses autores, o grau de utilização de procedimentos de investigação mais ou menos científicos. Como exemplo, podemos citar a linha que separa a formulação de Roberto Simonsen sobre o atraso ou o subcapitalismo, a qual não possuía a mesma sustentação, no campo da teoria econômica, da primorosa versão do subdesenvolvimento elaborada por Celso Furtado. Se o rigor separa esses dois autores (e também as obras e os momentos conjunturais), a perspectiva de totalidade na compreensão dos fenômenos sociais e a procura de uma teoria explicativa que ultrapasse a descrição funcional reúne-os. Usando a noção de famílias intelectuais, Simonsen e Furtado podem ser colocados lado a lado na matriz que confere ao Estado um papel fundamental na vida social e econômica, e a verdade é que, mesmo em campos ideológicos muito distintos, há um diálogo e uma tematização comum aos dois autores.

Mas há outras maneiras de conectar autores a linhagens de pensamento. A ilustração pode ser dada pela obra de Furtado, que pode aparecer não só no movimento do idealismo orgânico ${ }^{5}$, mas também inserido na nova moldura histórica que, ao enfrentar a nova agenda de problemas hegemonizada pela questão da modernização, origina (ou fortalece) a clivagem do pensamento radical de classe média. Dessa forma, as clivagens e as famílias realinham-se e rearranjam-se, estabelecendo novas formulações.

Já na discussão sobre o pensamento de Oliveiros Ferreira, Brandão trabalha tanto a questão da matriz do pensamento radical de classe média, quanto apresenta um problema muito mais sério. Ferreira, como Brandão, possui parte de sua experiência e produção intelectual mediada pela inserção acadêmica; são, ambos, resultado e parte das mudanças que atingem a universidade e os modelos de pesquisa. Ao analisar a resistência e o percurso da obra de Oliveiros Ferreira, nosso autor está tratando do momento nevrálgico em que a 'cientificização' da análise política impôs-se como a regra desses estudos. Ferreira foi ator no momento de inflexão da perspectiva holística, contraditória e histórica na análise da política para o momento da descrição, fragmentação e absenteísmo da produção institucional.

Nos capítulos seguintes, Brandão passeia seu olhar pelas barricadas e contrafortes que se ergueram para manter intacta uma escola de análise política e um vínculo desta com o compromisso moral da mudança6: o exemplo do Centro de Estudos de Cultural Contemporânea (Cedec), como instituição, e os estudos sobre desenvolvimento e democracia, elaborados pelo Núcleo de Apoio à Pesquisa sobre Democratização e Desenvolvimento (NADD), como projeto. O Cedec, porque procurou manter o principio de análise crítica e a interpretação interdisciplinar, o vínculo entre descrição, teorização e interpretação; o projeto sobre desenvolvimento

\footnotetext{
5 Malgrado a defesa da democracia como ponto de equilíbrio nas tendências de aparelhamento e despotismo estatal e tecnocrático, Furtado tem como ponto de partida que, na condição do subdesenvolvimento, as forças sociais são frágeis e o mercado auto-regulado (na economia e na política) não funciona.

6 Curiosamente, o debate sobre o papel da intelligentsia é pouco explorado por Brandão. Sendo leitor de Sartre, de quem cita A critica da razão dialética (2002), e de Mannheim, citando Ideologia e Utopia (1976), dois elementos, com fundamento nas teses desses dois autores, poderiam cimentar ainda mais a recusa ao modelo tecnicista e naturalista: a oposição entre "técnico e intelectual” (cf. SARTRE, 1994) e o compromisso moral do intelectual com os problemas do seu tempo (de Mannheim). Deste último, pode-se destacar ainda, como contribuição significativa a esse debate metodológico, a solução encontrada para a dicotomia entre o caráter axiológico dos temas sociais e a neutralidade exigida pelo conhecimento, por meio da idéia de síntese do pensamento social operada pelo intelectual (sem ela, este é ator e representante de grupo social).
} 
e democracia elaborado pelo NADD, pelo enfoque histórico e global dos dois grandes problemas que estiveram por debaixo do terreno do pensamento político e que na sua combinação e disposição forneceram a lógica para os projetos que modelaram o caminho da modernização nacional.

Os problemas de fundo que revestem a discussão pendular entre a Teoria Política (próxima da Filosofia e do espectro normativo) e a Ciência Política (empiria e descrição neutra) aparecem resumidos na seguinte formulação de Brandão: "Preocupado com a construção de meu objetivo, esboçarei alguns argumentos sobre o que parece construir princípios fundantes da ciência social e política institucionalizada: a compartimentalização do saber, a ruptura entre o normativo e o empírico, a separação entre a explicação científica e a explicação histórica, e o antagonismo entre teoria política e história da idéias. Na tentativa de relativizá-los, proporei a constituição ou a consolidação da teoria política como uma área de pesquisa interdisciplinar, autônoma intelectualmente, capaz de servir à educação política de homens socialmente empenhados e contribuir a internacionalização ativa e não passiva da ciência social que se faz na América do sul e no Brasil” (BRANDÃO, 2007, p. 189).

Duas ordens de questões parecem saltar desse enunciado: o esfacelamento da capacidade de entendimento da realidade social como uma unidade totalizante (da qual o caráter multidisciplinar e histórico é tão parte constitutiva quanto a exigência de uma teoria que funcione como explicação sistêmica para aquilo que, na experiência empírica e descritiva, é apenas parte morta e neutralizada) e a finalidade do próprio esforço e estratégia de conhecimento. Sem querer romper a barreira que separa um conhecimento objetivo sobre a política, da ação política mesma (como bem salientou Weber, em mais de uma ocasião), não se pode perder de vista que há uma função de destino ou um telos subjacente a todo empenho de entendimento e racionalização produzida pelo homem sobre o mundo natural e social. A denúncia da "crise do Esclarecimento", feita pela Escola de Frankfurt, em sua primeira geração de autores, incidia, na perspectiva de Adorno e Horkheimer (1985), na condição desviante entre uma racionalidade instrumental e uma racionalidade objetiva: a primeira pode perigosamente aproximar-se da inércia apontada mais tarde por autores tão diferentes como Fukuyama (1992), na concepção do fim da história, ou Habermas (1982; 2002), a partir da capacidade crescente de submissão do complexo da vida ao sistema; a segunda restabelece o nexo e o compromisso iluminista e republicano capazes de impedir que um interesse individualista radical e hedonista acabe por diluir as, agora tênues, barreiras que separam a polis do mercado.

A aparente objetividade e neutralidade de procedimentos científicos que recortam o processo político, desentranhando-o das tensões econômicas, ideológicas e cognitivas - nacionais e internacionais -, desterrando-o da dimensão histórica e política, não revelam também um modelo particular e uma visão de mundo muito específica? É importante que se tenha recusado a fórmula que converteu intelectuais em protagonistas políticos diretos, as escolhas inerentes à autonomia da vida pública em derivativos de construções técnicas legitimadas como "paradigmas científicos". Mas, ao recusarmos o destino público que o conhecimento alcança, inevitavelmente desarmamos a capacidade de deliberação social, deixando em aberto a produção de referências e explicações capazes de orientar a "tomada de decisão" e o cálculo dos custos e dos riscos sociais de longa duração.

Embora essa discussão tenha permeado os bastidores acadêmicos e de pesquisa, ora embutida na chamada crise das ideologias e dos paradigmas, da "monologia" do pensamento único, diluída no fenômeno da globalização econômica e da mundialização da cultura, poucos autores tiveram a coragem de trazer esse debate para a luz em um de seus principais locus de sustentação: a arena da produção do conhecimento e de suas balizas norteadoras, realizada nas instituições acadêmicas. Esse parece-me um dos destacados méritos do texto de Gildo Marçal Brandão. Seu trabalho procura, de maneira séria e comprometida, dar respostas para a área de pesquisa que se debate com os problemas de método e de interpretação sobre pensadores e pensamento social. De outro ângulo, não deixa de fora o controvertido projeto que se coloca hoje para a Ciência Política brasileira (ou latino-americana e, no largo espectro, mundial): o de validação no campo da ciência a partir da redução dos objetivos e do destino da pesquisa.

Não penso que devamos aderir ao enfoque dado por Brandão: não é necessária uma adesão incondicional e acrítica, mas o alerta deve servir para repensarmos o que estamos fazendo dentro das instituições de ensino e pesquisa e ao que isso serve. Como participantes de uma divisão do trabalho social e intelectual que se origina a partir do pressuposto de que todas as organizações sociais, mentalidades e valores emanam de nossas estruturas historicamente constituídas, é quase um imperativo ao cientista social e ao cientista político a obrigação contínua de objetivar e refletir criticamente sobre as condições de seu próprio trabalho. Dobrar a sociologia do conhecimento sobre si mesma e separá-la do estudo da sociologia da ciência e dos estudos da 
comunidade cientifica. Afinal, depois de Mannheim (1957; s/d), Merton (1970), Kuhn (1994) e Bourdieu (1989) não há qualquer chance de legitimarmos os procedimentos de conhecimento sem inseri-los no quadro maior das disputas políticas, que começam, impreterivelmente, no campo simbólico ${ }^{7}$.

Por último, penso que a leitura de Linhagens é extremamente importante tanto pela apresentação de sua teoria e método nos estudos de pensamento e da intelligentsia, mas muito mais pelo desafio sério e o chamamento ao debate que lança à comunidade dos cientistas sociais brasileiros. Por um lado ou por outro, aposto na rápida aceitação desse trabalho como uma referência na Ciência Política brasileira.

Vera Alves Cepêda (veracepeda@terra.com.br) é Doutora em Ciência Política pela Universidade de São Paulo (USP) e Professora do Departamento de Ciências Sociais e do Programa de Pós-Graduação em Ciência Política da Universidade Federal de São Carlos (UFSCar).

\section{REFERÊNCIASBIBLIOGRÁFICAS}

ADORNO, T. \& HORKHEIMER, M. 1985. Dialética do esclarecimento. $2^{\mathrm{a}}$ edição. Rio de Janeiro : Zahar.

BORDIEU, P. 1989. O poder simbólico. Rio de Janeiro : Bertrand Brasil.

BRANDÃO, G. M. 1997. A esquerda positiva - as duas almas do Partido Comunista brasileiro. São Paulo : Hucitec.

2007. Linhagens do pensamento político brasileiro. São Paulo : Hucitec.

CÂNDIDO, A. 1974. Entrevista com Antonio Cândido. Trans/form/ação, Marília, n. 1, p. 9-24.

FUKUYAMA, F. 1992. O fim da história e o último homem. Rio de Janeiro : Rocco.

HABERMAS, J. 1982. Conhecimento e interesse. Rio de Janeiro : Zahar.

2002. O discurso filosófico da modernidade. São Paulo : Martins Fontes.

KUHN, T. 1994. A estrutura das revoluções científicas. $3^{\mathrm{a}}$ edição. São Paulo : Perspectiva.

MANNHEIM, K. 1957. Ensayos de sociologia de la cultura. Madrid : Aguillar.

1976. Ideologia e utopia. Rio de Janeiro : Zahar.

s/d. Sociologia do conhecimento. V. I. Porto : Rés.

MERTON, R. 1970. Sociologia : teoria e estrutura. São Paulo : Mestre Jou.

MICELI, S. (org.). 2001. História das Ciências Sociais no Brasil. São Paulo : Sumaré.

OLIVEIRA VIANNA, F. J. 1927. O idealismo na Constituição. Rio de Janeiro : Globo.

1949. Instituições políticas brasileiras. 2 v. São Paulo : José Olympio.

1987. Populações meridionais do Brasil. 2 v. Niterói : Universidade Federal Fluminense.

SARTRE, J.-P. 1994. Em defesa dos intelectuais. São Paulo : Ática.

2002. Crítica da razão dialética. Rio de Janeiro : DP\&A.

\footnotetext{
7 Há em comum, no conjunto desses autores, a revelação (no processo histórico contemporâneo) de uma conversão ocorrida nos pressupostos da ciência: do paradigma da Verdade (tensão que recobriu desde sua origem o problema do grau de exatidão que separa as ciências da natureza das ciências da cultura) para o paradigma da validação (a hegemonia é conseguida na comunidade científica). Sem adentrarmos às questões que cercam objetividade, interpretação e validação das teorias e estudos desenvolvidos nessa fase, o caráter político, volitivo e a questão do consenso abrem o campo do político para um espaço que se propunha imune às escolhas - o procedimento científico.
} 